\title{
Diablotexto
}

\section{El nomadismo contemporáneo y el sentimiento de pertenencia. El jinete polaco, de Antonio Muñoz Molina y El viajero del siglo, de Andrés Neuman: dos casos paradigmáticos}

\author{
Contemporary nomadism and the sense of belonging. El jinete polaco, by \\ Antonio Muñoz Molina and El viajero del siglo, by Andrés Neuman: two \\ paradigmatic cases \\ IRINA ENACHE VIC \\ SORBONNE UNIVERSITÉ / UNIVERSITAT DE VALÈNCIA
}

\begin{abstract}
Resumen: Este artículo se propone estudiar el nomadismo contemporáneo y sus implicaciones identitarias en relación con la noción de pertenencia. Una reflexión antropológica y filosófica en tono al concepto de 'nomadismo' intentará evidenciar los fundamentos del revival contemporáneo de este fenómeno como modo cada vez más generalizado de estar en el mundo y distinguir, en la estela de Braidotti y Maffesoli, dos modalidades: el 'nomadismo desarraigado (o descentrado)' y el 'nomadismo dinámicamente arraigado'. Examinaremos sus características en los protagonistas de las novelas El jinete polaco (1991) de Antonio Muñoz Molina y El viajero del siglo (2009) de Andrés Neuman, que ilustran, a nuestro modo de ver, los dos tipos de identidades nómadas
\end{abstract}

Palabras clave: nomadismo, identidad, pertenencia, desarraigo, origen, El jinete polaco, El viajero del siglo

Abstract: This article aims to study the contemporary nomadism and its identity implications in relation to the notion of belonging. An anthropological y philosophical reflection on the concept of 'nomadism' will attempt to highlight the foundations of the contemporary revival of this phenomenon as an increasingly widespread way of being in the world and to distinguish, in the wake of Braidotti and Maffesoli, two modalities: 'uprooted (or decentered) nomadism' and 'dynamically rooted nomadism'. We will examine their characteristics in the protagonists of the novels El jinete polaco (1991) by Antonio Muñoz Molina and El viajero del siglo (2009) by Andrés Neuman, which illustrate, in our opinion, the two types of nomadic identities.

Key words: nomadism, identity, belonging, uprooting, origin, El jinete polaco, El viajero del siglo 
La novela El jinete polaco (1991) de Antonio Muñoz Molina ha gozado de mucha atención por parte de la crítica; pero en esta novela sobre la recuperación de un pasado personal y colectivo, se ha privilegiado casi siempre el tema de la memoria en relación más precisamente con una modalidad desideologizada de representar la Guerra civil y la posguerra (Ibáñez Ehrlich 2002; Mainer 1997; Villodre López 2009). Ahora bien, aplicando la teoría de Greimas, se observa que la necesidad de este largo proceso de rememoración solo se puede comprender diegéticamente desde la existencia nómada del protagonista. La búsqueda del 'objeto' (reconstitución de la identidad mediante la recuperación de la memoria personal y colectiva) resulta de una 'falta inicial': la incapacidad del protagonista de definir su lugar en el mundo tanto en el sentido concreto (espacial) como metafórico (identitario), es decir su sentimiento de pertenencia. El nomadismo es, como esperamos demostrar la manifestación de este descentramiento identitario.

El jinete polaco se abre con una pareja que llega al final de una búsqueda identitaria tras un recorrido regenerador por el pasado común. Las tres partes 'El reino de las voces', 'Jinete en la tormenta' y 'El jinete polaco' abordan una etapa distinta en la evolución de Manuel (la infancia, la adolescencia y la edad adulta) evidenciando la historia personal del protagonista. Esta biografía se confunde con el movimiento espacial, verdadero armazón diegético en el que se sustenta la novela. Manuel, pero también otros personajes con los que se relaciona, sale y vuelve a Mágina, su lugar de origen: son puntos que estructuran su recorrido diegético y entre los cuales se extiende la geografía movediza de una errancia profesional y exitencial entre varias metrópolis del mundo. El zigzaguear de una ciudad a otra, así como el movimiento de partida y retorno delinean una identidad marcada no solo por el tiempo del viaje mental retrospectivo, sino también por el espacio de un desplazamiento multidireccional.

La diégesis de la novela El viajero del siglo (2009) de Andrés Neuman se desarrolla en el siglo XIX. Pero a pesar de este cronotopo decimonónico, se trata, en las palabras del autor, de "una novela futurista que sucede en el pasado" o, según la editorial Alfaguara, que le otorgó el premio epónimo en 2009, de un "ambicioso experimento literario: [lee] el siglo XIX con la mirada del 
XXI. [...] Un puente entre la historia y los debates de nuestro presente global: la extranjería, el multiculturalismo y los nacionalismos, la emancipación de la mujer". Hans, el protagonista de esa novela, llega a Wandernburgo con la intención de quedarse una sola noche, como una etapa fugaz en su destino itinerante. Pero acaba quedándose un año ya que la ciudad le resulta intrigante, por su indeterminación geográfica y, atractiva por la gente que encuentra ahí. Traba amistad con Álvaro, un comerciante español con experiencias vitales multiculturales, y con un organillero cuya sabiduría, a pesar de cultivar la filosofía de lo "inmóvil", le fascina y estimula su reflexión sobre el mundo. Y también conoce ahí a Sophie, joven defensora de los derechos de la mujer que reúne en sus tertulias semanales a la pequeña burguesía ilustrada para debatir sobre las ideas avanzadas de su tiempo.

Ambas novelas aluden al nomadismo contemporáneo y sus implicaciones identitarias que se concentran en la noción de pertenencia. Nuestro análisis vendrá encabezado por un planteamiento teórico que intentará evidenciar los fundamentos del revival contemporáneo del nomadismo como nuevo modo de vivir y de estar en el mundo y visibilizar sus vínculos con la cuestión identitaria. Examinaremos luego las características específicas del nomadismo en los protagonistas de las dos novelas que ilustran, a nuestro modo de ver, dos tipos de identidades nómadas presentes en la literatura española contemporánea.

\section{El neonomadismo y la identidad desde el cambio cultural El nomadismo: una noción antropológica}

La idea que nos hacemos hoy en día del 'nomadismo' no es la que ha usado la antropología para definir la forma de vida geosocial itinerante de algunas tribus minoritarias. Toda una serie de transformaciones socioeconómicas y epistemológicas han ido modificando el imaginario nómada e imponen, a nuestro modo de ver, un uso resemantizado y una terminología renovada. Por 'neonomadismo' entendemos la nomadización de la sociedad en las últimas décadas, como resultado de aceleradas transformaciones socioeconómicos (los medios de comunicación, los transportes, las políticas transnacionales y la globalización), y de mutaciones epistemológicas que 
perciben el movimiento geográfico y metafórico como la forma dominante del sujeto contemporáneo de estar en el mundo. Este concepto cubre por tanto una doble esfera semántica, una concreta (geográfica) y otra metafórica (filosófica y existencial), ambas de igual importancia y de carácter complementario.

Según indica el DRAE, la palabra "nómada" proviene etimológicamente del latín nomas, -ădis, que a su vez lo recuperó del griego vouás, -ádos nomás, -ádos. Es el apelativo con el que los griegos designaron a los numidas, el famoso pueblo nómada norte africano (Lepelley), cuyo nombre tenía la misma resonancia que "apacentar" (vع́ $\omega \omega$, nemo), la actividad itinerante de este pueblo. El estilo de vida de los nómadas se caracteriza por desplazamientos en busca de condiciones propicias (climáticas o geográficas) para satisfacer sus necesidades de subsistencia. Este desplazamiento oportunista, que el geógrafo Manuel de Terán denomina el aprovechamiento, no concernía solo al pastoreo, sino también la caza, el comercio o la guerra (1952: 377-380). Cualquiera que sea su actividad nómada, el etnógrafo Thomas Barfield sostiene que el imaginario colectivo ha ido asociando a los nómadas con las tiendas de campaña en las que viven, símbolo de su movilidad perpetua: "[t]he very tents of the nomads are the sign of their ability to move at will and take their mobile livestock economy with them, throwing off old constraints and relationships" (Harrington: 2).

La variedad del nomadismo cobró un sesgo particular a principios del siglo XIX con el capitalismo industrial (llamado también primer capitalismo por oposición a su forma avanzada) puesto que, arguye Rolf Kailuweit, "[the] burgeoning capitalism requir[ed] flexible workers who [were] not tied down to a particular location" (2008: 9). La forma de vida de las tribus nómadas se expandió así a los pueblos sedentarios. Forzoso es notar que, si bien el "aprovechamiento" profesional sigue siendo la motivación, ya no se trata de una obligación impuesta por un ciclo natural, climático y geográfico, sino por un sistema económico que se convierte en el principio regulador de la movilidad de una parte de los sedentarios. La localización de los sitios industriales en la cercanía de grandes ciudades tiene dos consecuencias: en el mundo sedentario provoca el consabido éxodo rural, mientras que, si el nomadismo 
originario se movía entre lo rural y lo urbano según las necesidades, la localización en centros industriales imprime a este fenómeno una dimensión exclusivamente urbana. Asimismo, la nueva motivación personal incorpora a la dimensión colectiva y grupal un componente eminentemente individual.

En suma, con la revolución industrial, se nota un desplazamiento de la noción de nomadismo, que deja de remitir exclusivamente a un fenómeno etnográfico definitorio de las tribus nómadas para caracterizar ciertas formas de vida de las formaciones sociales con hábitos sedentarios. La llegada del capitalismo avanzado intensificará a tal punto el fenómeno del nomadismo urbano e individualizado que marcará una nueva etapa en la representación de esta noción.

\section{El Neonomadismo: una resemantización socioeconómica}

En la estela del nomadismo industrial del siglo XIX, a partir del mediados del siguiente ya no podemos hablar de "nomadismo" como fenómeno marginal que la ciencia o la literatura fue explorando desde la perspectiva sedentaria. En su visionario ensayo de 1990, The Freedom of Migrant: objections to nationalism sobre la incipiente pero vertiginosa propagación del llamado neonomadismo, Flusser propone una inusitada periodización de la humanidad utilizando este modo de vida como criterio: el Paleolítico dominado por el nomadismo (época de los pequeños grupos de cazadores-recolectores nómadas que se extendió hasta la invención de la agricultura, alrededor de 10.000 a.C.), el largo Neolítico cuando se impone el sedentarismo, y a partir de finales de los 80 del siglo $\mathrm{XX}$, el Nuevo Nomadismo provocado, según Flusser, por la revolución de la comunicación. A pesar de expresar algunas reservas con respecto al carácter radical de esta inversión, consideramos como Flusser que el modo de vida nómada, que se ha extendido cada vez más en la sociedad sedentaria, apunta hacia un cambio de paradigma.

En su fase más reciente, el nomadismo se origina sobre todo en la globalización, fenómeno propio del mundo posindustrial y neoliberal vigente, que Joan Oleza define como: "configuración de un único mercado mundial, la transformación de las empresas multinacionales en empresas globales, la extensión planetaria de las operaciones del capital financiero, la 
universalización de la tecnología, la autoridad de instituciones internacionales" (2004: 9). Este proceso socioeconómico, tecnológico y empresarial a escala global ha provocado la movilidad laboral llevando la migración de la mano de obra a niveles nunca alcanzados previamente (a pesar de su presencia en la era industrial). Esta circulación masiva ha sido facilitada y potenciada por la diversificación, los avances y la accesibilidad económica de los transportes, que también desbordaron el marco laboral revolucionando las costumbres viajeras del individuo. La localización de los grandes centros económicos en las grandes ciudades las ha convertido en focos de efervescencia multicultural, pero también de inestabilidad local de sus habitantes: dentro de un paisaje global movedizo, los "neonómadas", atrapados en un desplazamiento continuo, se mueven de un lugar de paso a otro, entre puntos dispersos de estancia provisional. Por lo tanto, entre las características propias de este nomadismo contemporáneo salta a la vista la intensificación de lo urbano (que a menudo es cosmopolita), pero sobre todo su incremento alimentado por la globalización laboral y el desarrollo de los transportes. Según los pensadores nomadófilos Vilém Flusser y Michel Maffesoli, se ha llegado incluso a una inversión de proporciones a expensas del antes dominante sedentarismo. Incluso la historia ya no se cuenta exclusivamente desde el punto de vista del sedentario que veía en el nómada la figura de un 'otro' "both attractive and repellant" (Harrington, 2012: 2); el nómada se ha convertido en protagonista de su propio discurso si pensamos en su amplia presencia como protagonista en la literatura actual. En opinión del sociólogo francés, "[l]e mouvement ou l'effervescence est dans toutes les têtes" (1997: 24-5), y esta tendencia es propia del momento epistémico vigente: "Il y a de l'ensauvagement dans l'air du temps" (ídem).

\section{El neonomadismo: una resemantización epistemológica y cultural}

La resemantización epistemológica desborda la esfera de los cambios estrictamente socioeconómicos y engloba una dimensión metafórica del neonomadismo, que se ha extendido de manera exponencial solo a partir de mediados del siglo XX para el mundo contemporáneo. Así, el neonomadismo cobraría una significación filosófica y existencial: no sería solo un deambular 
por el mundo, sino también un pasar con rapidez de una comunidad a otra, de un sistema a otro, de una experiencia a otra, en fin de una identidad a otra.

\section{El nomadismo contemporáneo: dos posicionamientos}

La sociedad premoderna de las comunidades sedentarias occidentales era una expresión de la Familia, el Estado y la Iglesia donde las identidades eran asignadas y fijas a lo largo de la vida. Estaba regida por el principio centralizador de cuius regio, eius natio que fortalecía el sentimiento de pertenencia del individuo a una comunidad. Según los teóricos culturales, el momento de ruptura con esta estructura empieza en la Modernidad con lo que Antony Giddens denomina 'desanclaje': la desintegración de la configuración tradicional regida por categorías simbólicas con poder identitario vinculante (familia, vecindad, religión, nación y trabajo en gremios), que ofrecían al sujeto un sentimiento de pertenencia a una comunidad y una identidad única y socialmente unitaria. La desintegración de estas formaciones obliga al individuo a reintegrarse en nuevas redes sociales a fin de edificarse una identidad.

Este proceso progresivo de desanclaje alcanza en le posmodernidad una aceleración vertiginosa y a partir de mediados del siglo pasado se acentúan fenómenos modernos como la autodeterminación del individuo, la desaparición progresiva de las balizas, y la débil presencia reguladora de las instituciones y del estado. Simultáneamente, los grandes relatos dejan de regir como antes las preocupaciones y las existencias individuales. La revolución de la comunicación, la globalización y el transporte han multiplicado de manera exponencial las posibilidades electivas nacientes en la Modernidad. El único guía es la libertad del propio deseo entre la multitud de opciones. En la era de la nomadización, la fluidización de la experiencia y la identidad corre parejas con la movilidad geográfica y cultural.

En las últimas décadas, el tema del nomadismo ha ganado protagonismo en la literatura española e internacional. Si aparece siempre relacionado con la identidad, se pueden distinguir dos maneras de percibirlo: como un nuevo modo de ser de los personajes que ahora se definen con respecto a un movimiento percibido como liberador, o bien, como lo que los trastorna convirtiéndolos en seres "desplazados", sin referencias, fuera de 
lugar. Estos dos tipos resultan a nuestro modo de ver de dos tendencias de pensamiento contemporáneo que se han decantado en torno al nomadismo.

Dentro de la primera tendencia, se sitúa el movimiento epistemológico iniciado por Deleuze et Guattari en el contexto del mayo 68 en torno a lo que llamaron 'nomadología'. En su libro de honda resonancia Mille plateaux, los filósofos proponían el nomadismo como modelo alternativo para contrarrestar el discurso dominante: el desplazamiento libre y mutidireccional encarnado por la metáfora del rizoma ha de oponerse al modelo estatal (forma arborescente). Sin ser "deleuziano", más tarde el sociólogo francés Michel Maffesoli condena también la lógica esclerotizante de lo que denomina "assignement à résidence" operado por el Estado moderno oponiéndole la vitalicia "pulsion d'errance". Según el sociólogo, el Estado-nación normativo, inflexible y abstracto terminó pareciéndole al individuo un encierro claustrofóbico del que debía liberarse. En el contexto de la globalización y la revolución tecnológica que analiza, Maffesoli celebra el nomadismo metafórico que contrarresta el antiguo orden invadiendo todos los campos (trabajo, consumo, turismo, ideologías, relaciones sociales). En la vida cotidiana, el encuentro sistemático con el exterior, lo nuevo, lo extraño permite experimentar la pluralidad estructural de la psique humana, enriquecerse a partir de ello: "[le] nomadisme contemporain [...] fragilise l'identité, il fait communier à la nature, il réinvente un lien social tout à la fois plus évanesccent est plus intense [...] rejouant tout à la fois la dynamique de l'exil et celle de la réintégration" (1997: 24). Esta visión del nomadismo puede ser tanto móvil como 'inmovil' en la medida en que, incluso cuando el individuo permanece en un solo lugar, se construye culturalmente de manera pluridireccional. Según el sociólogo francés, es necesario enraizarse, pero esto no ha de encerrar al sujeto en el inmovilismo y aniquilar sus impulsos constructivos: al contrario, mediante lo que Maffesoli llama "enracinement dynamique", el individuo puede permanecer abierto y disponible a elementos nuevos y desarrollarse plenamente en una especie de disponibilidad centrada.

Construyendo su ensayo alrededor del pensamiento deleuziano, la filósofa australiana Rosi Braidotti (Nomadic Subjects, 2010) desarrolla la dimensión eminentemente espacial del nomadismo estudiando el impacto de la actual movilidad geográfica en la identidad personal. Si se han de suprimir las 
divisiones y las categorías impuestas por el Estado, también se deben reconsiderar la concepción tradicional del espacio y de las fronteras. Según Deleuze y Guattari, el nómada cuestiona la idea de fronteras puesto que está en perpetuo desplazamiento. En cambio, para Braidotti, no se trata de suprimir estas fronteras sino de tener plena conciencia de su existencia y, a la vez, de su extrema porosidad: el nómada braidottiano vive con las fronteras y las experimenta naturalmente como una forma de vida y de identidad: "It is the intense desire to go on transpassing, transgressing" (2011: 36). El enfoque nómada de las fronteras incide en la cuestión identitaria puesto que una concepción fluida de las fronteras implica la fluidez, la no fijeza de las identidades que se modulan al ritmo de los desplazamientos transnacionales. Insertándose en la línea de pensamiento iniciada con la crisis de la modernidad, Braidotti cuestiona por tanto la percepción unitaria y estable de la identidad cultural y personal subrayando la riqueza de la identidad nómada que se encuentra en un constante proceso de hibridación: el nómada "never takes on fully the limits of one national, fixed identity" (33), sino que se convierte en un crisol de huellas geográficas y culturales, en el reflejo del perpetuo "shifting landskape" (33) en el que se mueve. A su modo de ver, el nomadismo no encarna "homelessness or compulsive displacement: it is rather a figuration for the kind of subject who has relinquished all idea, desire, or nostalgia for fixity" (57).

Desde perspectivas distintas, los estos pensadores subrayan las potencialidades del nomadismo en sus acepciones geográficas y/o metafóricas. Como discurso alternativo antiestatal, como modo de vida "enraizado dinámicamente" y como modo de ser y de experiencia que ha integrado la frontera como elemento constitutivo, pero no limitativo, el nomadismo parece ser para estos filósofos una forma de vida positivamente polifacética y liberadora. El nomadismo tiende a concebirse como la forma adecuada para la construcción de la identidad, que ya no podría definirse en términos sedentarios y exclusivistas.

El sentimiento de pertenencia puede nacer tanto en una relación exclusiva con un determinado espacio o comunidad como de una relación flexible; pero para conseguir el equilibrio identitario este lazo ha de ser en 
cualquier caso 'robusto' es decir identificar en el movimiento y lo múltiple una posibilidad de sentido vertebrador para el sujeto. Para los nomadófilos, la "transnational place-polygamy", en palabras de Ulrich Beck, puede por tanto ser compatible con la pluripertenencia sin tener "nostalgia for fixity", centro u origen. No hay vuelta hacia un centro original o identitario como la línea reversible de un viaje de ida y vuelta entre un punto $A$ y un punto $B$ : el neonomadismo sigue precisamente un movimiento zigzagueante y continuo. La maleabilidad les aparece como lo propio de la identidad y el nomadismo, como forma natural de estar en el mundo.

Otros teóricos han desarrollado la cuestión de la identidad y del neonomadismo en términos más sombríos: el descentramiento de las estructuras simbólicas y la exposición del individuo a una sobreabundancia de signos, oportunidades y paisajes llevarían a su alienación por falta de asideros sólidos. Es el segundo posicionamiento que anunciábamos.

En opinión de Bauman (2010), el debilitamiento del sentimiento fuerte de identidad se origina en la desaparición de la supremacía, antes incontestable e indivisible, del Estado-nación, cuya entrada en los mercados internacionales ha visto erosionarse su centralismo y el sentimiento de patriotismo del individuo. Asimismo, la desaparición de las grandes utopías en las que el individuo podía invertir su energía vital imposibilitó las empresas otorgadoras de sentido. En Maffesoli, el sujeto se libera de un estado que se concibe como rígido. En Bauman, el debilitamiento del consistente zócalo representado por el Estado y la desaparición de los focos ideológicos han llevado a cierto vacío simbólico, un terreno movedizo en el que las identidades no se podían anclar sólidamente. Pero este desmantelamiento desencadena, en la visión baumaniana, la crisis del sentimiento de pertenencia y de ahí la crisis de la identidad.

A diferencia del nómada enraizado dinámicamente, este tipo de nómada contemporáneo es vulnerable, consciente o inconscientemente, a los efectos de la pérdida de las categorías simbólicas. Para él, la pertenencia tiene, desde el punto de vista espacial, el sentido clásico de "procedencia", de lugar de origen, o sea la casa, una ciudad o una nación, porque "le lieu de naissance est constitutif de l'identité individuelle" (1991: 71), advierte Marc Augé. 
Aparte del desmantelamiento de las instancias otorgadoras de sentido, está también afectado por la dinámica de aceleración a gran escala del mundo contemporáneo. El antropólogo Marc Augé evoca una aceleración de la historia: lo que el teórico denomina "surabondance événementielle du présent" se desglosa en el desmoronamiento brusco y vertiginoso de los regímenes, las crisis políticas y socioeconómicas de los países liberales o bien el exceso de información (1991: 40-1). Bajo el mismo signo del exceso, está la "surabondance spatiale du présent" representada por "la multiplication des références imagées et imaginaires, et dans les spectaculaires accélérations des moyens de transport" (1991: 47-8). Según Augé, no es que el mundo ya no tenga sentido, sino que ante la polimorfa multiplicación contemporánea "nous [éprouvons] explicitement et intensément le besoin quotidien de lui en donner un [...] de donner un sens au présent" (1991: 41-2). Dentro de la metáfora del nomadismo, el individuo ha de construirse en un espacio físico y simbólico ilimitado y desprovisto de balizas claras y sólidas: "[n]otre modernité liquide [...] célèbre l'individu nomade et sans entraves", comenta Bauman (2010: 44). El neonómada acaba navegando entre cantidad de proyectos a corto plazo y entre identidades posibles. En esta falta de constancia y de compromiso, se cambian frenéticamente países, ciudades, empleos, amores, identidades... probarlos todos sin jurar fidelidad a ninguno.

Existe en la psique humana un deseo que empuja al hombre a perseguir siempre otra cosa. Esta predisposición fundacional del ser humano de no poder quedarse quieto en un lugar, que hace siglos comentaba Blaise Pascal, encuentra en la contemporaneidad un fértil terreno de desarrollo. Bauman usa la noción de disembeddedness de Giddens para caracterizar este estado vital de perpetuo 'desanclaje' y movimiento: "There is no prospect of a 'final reembeddedness' at the end of the road; being on the road has become the permanent way of life of the (now chronically) disembedded individuals" (2009: 6). En teóricos como Bauman y Giddens, la imposibilidad de 'reanclaje' aparece como un factor generador de desequilibrio identitario: dentro de una lógica de lo efímero, el camino se fragmenta en una sucesión de paradas y resulta más difícil elaborar sentido. Mucho movimiento y poco anclaje simbólico. Estas experiencias no conseguirían ser vertebradoras para la existencia del individuo. 
Por el contrario, los nomadófilos defienden un tipo de nómada que negocia constante y felizmente entre varias pertenencias sin perseguir un origen alguno o nueva fijación. Con cada nuevo paisaje, lengua o cultura puede por tanto emerger un diálogo simbólico y perpetuamente regenerador. La "conciencia nómada", en palabras de Braidotti, es dialógica pero no alienada, es crítica, atenta y selectiva. A modo de ilustración metafórica de esta dimensión falaz del destino, citamos un sintomático anuncio de periódico evocado por Bauman para referir el estado de desanclaje del hombre contemporáneo: "Have car, can travel; awaiting propositions" (2009: 7). Según el sociólogo polaco, la sensibilidad contemporánea se traduciría por la disponibilidad por el movimiento y la opacidad de la meta. Caminos sin destino verdadero y movimiento desimbolizado que parece avanzar por su propia inercia. El nomadismo geográfico sería en este marco una manifestación concreta de la inestabilidad y la busca permanente de cambio y movimiento propio del Zeitgeist contemporáneo. Un nomadismo tanto geográfico como simbólico: al ser expansivo y sin balizas, genera un vacío que aporta solo la ilusión de la satisfacción efímera.

De estas experiencias se espera inconscientemente que colmen el vacío de sentido instaurado con el declive de los marcos de referencia sólidos y con la aceleración y la fragmentación del mundo. Retomando la terminología de Braidotti, el nomadismo que resulta de este marco implicaría un sentimiento de "homelessness" y/o la más o menos consciente "nostalgia for fixity"; se trata en este caso del desplazamiento compulsivo, opuesto a la "conciencia nómada".

Es un 'nómada desarraigado y descentrado' que, a diferencia del 'nómada arraigado dinámicamente' tiene lazos flojos con el espacio en el que se desenvuelve y se define por el descentramiento identitario. Está desplazado, está fuera del lugar. A partir de la noción heideggeriana de dasein, Víctor Granado Almena distingue entre "estar" físicamente en un lugar (como cualquier objeto) y "residir" o "habitar", que sería la significación verdadera de la fórmula "estar-en-el-mundo". Esta modalidad particular de "estar-en" implicaría que al "habitar" en algo, este espacio dejaría de ser un objeto y se convertiría en "parte de nosotros invadiendo y penetrando en nuestra relación con los demás objetos del mundo, una relación entre el yo y aquello en lo que habito 
que no puede entenderse como un tipo de relación sujeto-objeto" (2016: 102). Recuperando la visión de Granado Almena, el nómada descentrado "dej[a] de tener mundo para estar meramente en el espacio" (ídem), pierde esta relación de co-pertenencia.

En este contexto, el movimiento se convierte a menudo en válvula de escape. El individuo necesita intensidad y acción, necesita el movimiento perpetuo para conseguir una ilusión de sentido. En esta perspectiva teórica, el neonomadismo aparecería más como huida en su sentido concreto y figurado. En el buscar inconsciente de experiencias múltiples para colmar bien que mal un vacío no hay simbolización; estas experiencias aparecen según los teóricos antes citados como momentos de satisfacción fugaces y constantemente reinicializados en un encadenamiento nómada sin fin, a menudo alienante, de un lugar-deseo a otro. El 'neonómada arraigado dinámicamente' expresa su aparente paradoja en la capacidad de estar centrado en el movimiento mismo como modalidad de ser; su identidad, a pesar de la heterogeneidad y el cambio que la constituyen, se cohesiona alrededor del sentido y adquiere de golpe una dimensión simbólica.

\section{El jinete polaco y El viajero del siglo: dos novelas paradigmáticas del neonomadismo}

\section{Origen y pertenencia}

A partir del tercer milenio, la literatura llamada "en tránsito", de la "desterritorialización" o transnacional se sitúa de lleno en el debate del neonomadismo desarraigado por oposición a uno arraigado dinámicamente. Escritores como Andrés Neuman, Juan Carlos Méndez Guédez, Ignacio Padilla, Santiago Roncagliolo o Fernando Iwasaki han vivido en varios países y pertenecen a una era caracterizada por la transnacionalización de la cultura y de la industria editorial. Muchos se autodeclaran "apátridas": no solo producen obras lejos de sus coordenadas nacionales de origen, sino que impulsan en sus obras una visión transnacional del individuo rechazando también en sus posicionamientos públicos la asignación exclusiva a un solo territorio o una sola patria. Son obras que problematizan la noción de frontera geográfica y cultural 
a través de personajes con una capacidad elevada para desterritorializarse y reterritorializarse. El movimiento es zigzagueante: no hay vuelta física o imaginaria a un verdadero centro.

El protagonista de El viajero del siglo rechaza la asociación del individuo con una sola patria. Para Hans, la idea tradicional del origen como factor definitorio de la identidad personal y centro fundacional de arraigo no tiene fundamento: "el origen de una persona es un simple accidente, somos del lugar donde estamos" (181). El origen parece equivaler a un determinismo identitario puesto que el ser se concibe como el resultado de tantos otros lugares en los que ha vivido, cosas que ha experimentado o personas que ha encontrado. $A$ su amigo Álvaro, el protagonista le contesta:

no creo que nos guíen las patrias, nos mueven las personas que pueden ser de cualquier parte) [...] (nos mueven los idiomas, continuó Hans, que pueden aprenderse, o los recuerdos [...] ¿qué pasa si tus recuerdos están en lugres y momentos diferentes?, ¿entonces cuales te pertenecen más?" (2009: 108).

Las experiencias, las personas, los recuerdos son diferentes, móviles y potencialmente de cualquier parte y se oponen a la fijeza de un espacio centralizado. La pertenencia es por tanto variable y portátil. Piensa además que el apego exclusivo a un lugar puede engendrar una esclavitud emocional; así lo dice cuando cita las palabras de Chrétien de Troyes: "los que creen que en el lugar donde nacieron es su patria, sufren. Los que creen que cualquier lugar podría ser su patria, sufren menos. $Y$ los que saben que ningún lugar será su patria, esos son invulnerables" (2009: 123). Para Hans, el equilibrio es incompatible con una pertenencia exclusiva.

El movimiento es precisamente lo que define al protagonista. Si acaba quedándose mucho más tiempo de lo previsto en Wandernburgo es porque la ciudad encarna simbólicamente las precedentes ideas de pluripertenencia y movimiento. Situada en "una zona que siempre ha basculado entre Sajonia y Prusia sin un dominio claro" (2009: 84), es decir sin obediencia estatal exclusiva. Por otra parte, su nombre evocador ("wandern" < "caminar, vagar") se hace eco de la movilidad que la caracteriza puesto que sus calles parecen cambiar constantemente de posición. La paradoja de la fijeza —propia del 
espacio- y una extraña movilidad hace que los viajeros que visitan Wandernburgo acaben quedándose, como Álvaro que "llev[a] de paso aquí más de diez años" (2009: 88).

La visión de Hans sobre la centralidad se refleja también metafóricamente en sus ideas sobre la geopolítica y la estética. Durante las tertulias animadas por Sophie, el "viajero del siglo" apuesta por suprimir la frontera y la aduana e instalar un federalismo descentralizado tal como recomendaba Kant (100): “¿para qué un centro único?, un lugar obligatorio?, yo estoy a favor de la unificación, no de la centralización" (2009: 206-7). En la polémica literaria, cuestiona la visión jerarquizada de la crítica defendida por el profesor Mietter: "evitar el centralismo del gusto. Como espero que las letras sigan siendo una república, prefiero el federalismo estético" (2009: 225). Para el protagonista, la descentralización ha de ser también un fundamento estético.

En otros escritores de la era nómada, "la casa", "la nación” permanece poderoso. La solidez del apego a un origen o a un determinado lugar se encuentra en la literatura leonesa o vasca en la cual palpitan la identidad y los rasgos específicos de lo local (Bernardo Atxaga, Luis Mateo Díez, José María Merino, Julio Llamazares, Andrés Trapiello). A diferencia de estos escritores, otros como Kirmen Uribe (Bilbao-New York-Bilbao, 2008), Patricio Pron (El espíritu de mis padres sigue subiendo en la lluvia, 2011) o Clara Obligado Marcó del Pont (Una casa lejos, 2020) plantean el terruño y el origen en dialéctica con la movilidad geográfica. En estas obras, el origen aparece, en distintos modos, como un factor de gran incidencia en la dinámica identitaria.

En El jinete polaco, el centro, el origen, como la casa de su infancia o el terruño, son esenciales. En su intento de aislar los valores de la intimidad del espacio interior, Gaston Bachelard consideraba que el afecto experimentado hacia el hogar nos permite enraizarnos en algún lugar en el mundo (1974: cap. 1). Los recuerdos de Manuel del primer capítulo gravitan alrededor de esta cuna "athropocosmique" (Augé, 1991), que conforman la casa, la familia y el pueblo con sus calles y lugares donde palpitan la vida y las historias de su gente. En esta casa que "se [le] antojaba inacabable", el joven Manuel exploraba con la curiosidad de aventurero miles de rincones y recovecos: se colaba "en los graneros donde jugaba a nadar en un océano de trigo" (1991: 
$2548^{1}$ ) o bien recorría "la casa y encontraba tesoros tras la puerta del pajar y llanuras blancas de polvo debajo de las camas y selvas incandescentes en el fuego" (1991: 2634). Según Bachelard, lugares como el granero, los rincones o los pasadizos potencian experiencias y aumentan así el poder identificatorio.

Mágina encierra un similar potencial de engendrar el sentimiento de pertenencia por representar lo que Marc Augé llama "lugar antropológico", que, a su modo de ver, tiene una dimensión identitaria, relacional e histórica (1991: 69). A diferencia del espacio cosmopolita del Manuel adulto marcado por los intercambios triviales, el anonimato y la soledad, en Mágina, los personajes interaccionan constantemente y la densidad de su experiencia está amplificada por el carácter insular del pueblo. La vida gira alrededor del centro constituido por la plaza y su monumento central del general Orduña, la torre del reloj, la iglesia Santa María, el ayuntamiento, la comisaría y el consultorio de don Mercurio. Es el punto donde se cruzan las trayectorias individuales. En estos verdaderos epicentros sociales trasparece la vitalidad de un organismo humano colectivo.

La dimensión histórica se refleja en la presencia indirecta pero persistente de los antepasados, como pasa en otros tantos territorios míticos (Celama, Comala, Macondo...) donde el pasado reverbera o incluso convive con el presente. Por una parte, generaciones sucesivas usan los mismos códigos, costumbres y saberes inspirados por la naturaleza: el calendario agrícola inmutable de la siega, la vendimia y la aceituna (Molina, 1991: 2222) o la repetitividad inalterable del tiempo rural regulado por las campanas de la iglesia o la trompeta del cuartel (483). Por otra parte, el pasado y los antepasados palpitan en la memoria local transmitida oralmente, que a menudo está envuelta en el mito. La leyenda sobre la momia de la Casa de las Torres se recupera, por ejemplo, y se transmite enriqueciéndose con la versión de cada habitante: el abuelo Manuel (339), las mujeres que llenan sus cantaros (339) o los niños que la recuentan excitados por el miedo (2756). En este proceso de recuperar, transformar y transmitir la leyenda, cada uno invierte su subjetividad aumentando así su sentimiento de pertenencia a una tradición

\footnotetext{
${ }^{1}$ La numeración de páginas de El jinete polaco corresponde a una version Kindle de la novela (8446 páginas).
} 
ancestral. La casa, la familia, el espacio estrecho de intercambio y la memoria ancestral plasman una subjetividad profundamente enraizada en una comunidad y una identidad ligada al origen: "por más que quiera uno tiene un solo idioma y una sola patria, aunque reniegue de ella, y hasta es posible que una sola ciudad y un único paisaje" (5843).

La ruptura del adolescente con Mágina no es solo el gesto arquetípico de matar al padre, o sea renegar del espacio nativo para poder luego regresar ya propietario de él. Es también el nomadismo cultural de buscar la pertenencia en sistemas culturales lejanos. Ambas interpretaciones traducen la búsqueda de una afiliación tras el rechazo de la filiación. Pero el proyecto afiliativo esbozado por las "palabras prestigiosas, adornadas por las mayúsculas de la literatura" acabará fracasando. Entre las voces rechazadas de las identificaciones primarias (de la familia y del terruño) y las anacrónicas de una emancipación soñada (la cultura anglosajona), el joven Manuel ha perdido la potencialidad de pertenencia. El periplo de la identidad adolescente que determinará la existencia adulta del protagonista termina por tanto en un doble estado disfórico: un limbo amargo entre un pasado rechazado y un futuro desengañado.

El personaje de Hans también parece dar la espalda al pasado. Cuando Sophie le reprocha no saber nada sobre su vida misteriosa, le contesta:

claro que me conoces. Sabes muy bien quién soy. Conoces mis opiniones, compartes mis gustos, comprendes mis reacciones. Y además casi siempre adivinas lo que siento. ¿Hay mayor conocimiento que ese? [...] Estoy aquí contigo, dijo él, qué mejor historia que esa. (Neuman, 2009: 182)

Geneviève Champeau observa que el protagonista "borra las huellas de su pasado y se encamina hacia un porvenir incierto, en un perpetuo hacerse antiesencialista" (2017: 318). Si bien es cierto que Hans desconsidera el pasado y defiende la manifestación de sí mismo en un presente siempre renovado, no se trata de un rechazo o un malestar como en Manuel.

Antes de la correcuperación del pasado con Nadia, la identidad de Manuel permanecerá en ruptura con su antiguo centro vital. El sentimiento de desarraigo, la nostalgia y el amor por su familia no podrán contrarrestar una 
culpabilidad y un desfase identitario que el paso del tiempo irá ahondando cada vez más. Desaparecen las antiguas referencias que solían arraigar al personaje de Manuel en la identidad colectiva. En la familia, cambia la figura tutelar y a la vez entrañable del abuelo consumido por la decrepitud: "avanza palmo a palmo apoyándose en el bastón, en la mesa, en los espaldares de las sillas, respirando como si tuviera en los bronquios telarañas o piedras" (Molina, 1991: 1244). Pero, sobre todo se ha desvanecido en su abuelo la vivacidad narrativa que le había plasmado un universo infantil de fantasía: "[é]l, que para mí fue el héroe de todas las aventuras [...], ya apenas sonríe y casi no habla, tan aletargado en el silencio como en la pantanosa inmovilidad de su cuerpo" (1273-8). En sus "paréntesis apresurado[s] entre dos viajes", los intentos de reanudar con su terruño fracasan a causa de una desidentificación con el lugar de hoy y el de ayer:

\footnotetext{
ha vuelto de vez en cuando a su país con el propósito de quedarse y se ha marchado con un sentimiento cada vez más intenso de extrañeza y de asco, aturdido por el tráfico, por las máquinas tragaperras de los bares, por el ruido intolerable de los martillos neumáticos en las aceras reventadas, por la codicia sin escrúpulos y la sonriente apostasía que han transfigurado las caras de muchos a los que conoció antes de irse.
}

La constatación del cambio lleva a la desilusión y la desidentificación con el lugar de origen: "ése es ahora el lugar que fue el centro de mi vida" (1276). Pertenecer no es sentirse pertenecer: para Manuel adulto, como lo fue para el adolescente, no resultan suficientes los atributos intrínsecos de Mágina como lugar "antropológico" y mítico con potencial identificatorio. En un mapa del que ha ido borrando su antiguo centro de gravedad, el joven traductor avanza como funámbulo zigzagueando entre no lugares cosmopolitas.

\section{Experimentar el presente del movimiento: entre arraigo y desarraigo}

Los protagonistas nómadas de las dos novelas descartan de la ecuación el pasado y el futuro y permanecen en el presente del movimiento continuo. En El jinete polaco, en que el tema de la temporalidad es mucho más presente, el cotidiano de Manuel está regulado sistemáticamente por artefactos o formas de la instantaneidad. Tablones electrónicos y relojes indican el tiempo objetivo reactualizando las horas de llegada y de salida de trenes, aviones y congresos ("se deslizan los puntos de destino y los horarios de los trenes a lo largo de los 
indicadores electrónicos", 7608), mientras que su profesión de traductor simultáneo lo ancla en el proceso presente de atrapar y metamorfosear las palabras ("en el instante en que suenan y convertirlas en otras unas décimas de segundo después", 6566). El presente es para Hans un fundamento existencial porque en él nace el ritmo, lo nuevo y la posibilidad de cambio. Cada nuevo lugar o cada nueva experiencia es una ocasión para asombrarse: "cuando viajo todo me parece parece un misterio, incluso antes de llegar" (120). Pero esto no impide que se demore mucho tiempo en algún lugar como Wandernburgo, que le atrae con su extraña geografía y las experiencias humanas - gratas y algunas veces complejas - que le ofrece. La partida se posterga cuando aparece la posibilidad de experimentar plenamente lo local y explorar la alteridad arraigándose así simbólicamente en el espacio.

En Manuel el movimiento tanto geográfico como metafórico es incesante. La urgencia de los encargos profesionales lo ata al presente y parecen imponerle un estado permanente de prisa: "las agujas de su reloj de pulsera [indican] que se van acercando a la hora de la partida" (6411). En la existencia cosmopolita del personaje, hemos inventariado por lo menos una decena de fórmulas relacionadas con la idea de prisa $(3566,5823,6240,6411$, 6498, 6786, 8367, 7608, 7611, 7617, 6135). Estas obligaciones profesionales parecen transformarlo en un ejecutante, privándolo del uso libre, volitivo y emancipatorio del tiempo. El personaje de Hans, por el contrario, impone a la realidad su propia temporalidad personal: "no les veo utilidad a los relojes, nunca marcan la hora que necesito" (105). Muy al contrario del espíritu germanista, Hans comparte con el personaje de Nadia la misma "falta absoluta de sentido del tiempo" (5259). La mujer que le abrirá a Manuel las puertas de la exploración del pasado y de sí mismo, es traductora también; frecuenta los mismos ámbitos laborales internacionales, pero mantiene con el tiempo una relación sumamente distinta:

\footnotetext{
ni se te ocurre la posibilidad de perder el vuelo, tan serena que muy probablemente apurarás el último minuto deambulando sin prisa por la tienda libre de impuestos y serás la última pasajera que suba al avión, sonriendo siempre a un paso del desastre que no llega a ocurrir (8399)
} 
Nadia percibe el tiempo objetivo del calendario y los relojes como exterior e incompatible con el fluir sereno de una especie de temporalidad personal inquebrantable: se instala en el tiempo a sus anchas y parece ajustar las obligaciones a sus propias exigencias.

Por lo general, la prisa remite a la (in)capacidad de hombre de responder a las limitaciones temporales que impone la vida cotidiana. Pero en Manuel lo más a menudo su "prisa de neurótico" desborda la esfera del pragmatismo cotidiano describiendo un nerviosismo incontrolado de actividades cotidianas que no están regidas por limitaciones de tiempo: "[s]ólo fumo hasta la mitad los cigarrillos, no termino el café y me dejo el sandwich casi entero, actos inacabados, decisiones que no llego a cumplir" (7611). La excitación permanente e injustificada encuentra en el valium de cabecera y la petaca de Glenfiddich los paliativos indispensables para seguir sin gloria y a menudo en el borde del naufragio: "cápsula de valium, las graduales artimañas urdidas para sobrevivir sin entusiasmo" (5716).

A nuestro modo de ver, esta prisa frenética y más bien patológica del protagonista no procede solo de las obligaciones profesionales: la prisa podría ser la necesidad inconsciente de llenar un vacío y la relación con el tiempo, una metáfora del malestar identitario del protagonista. Veamos con más detenimiento la cita siguiente:

\begin{abstract}
[fui arrastrado por] la prisa cegadora y creciente [...], sin que participaran en ella ni mi voluntad ni mi conciencia, era como cuando uno va por una calle del centro a la hora de salida de las oficinas y aunque no tenga nada que hacer apresura el paso para igualar el ritmo de la multitud, embebido y tragado por ella, una velocidad que parece energía y es el vértigo de la caída libre, no detenerse nunca, no perder ni una de las palabras escuchadas en el auricular, no quedarse solo a una cierta hora de la noche, no llegar tarde al trabajo ni al mostrador de facturación del aeropuerto, añadir cada minuto al próximo sin mirar la delgada fisura de vacío que hay entre los dos, una copa tras otra, un viaje emprendido al terminar el anterior, una réplica instantánea en una conversación amenazada por el silencio, un bar nocturno y luego un taxi y otro bar que cierra un poco más tarde, la urgencia angustiosa de apurar la noche y de que la noche no se termine. $(5823)^{2}$
\end{abstract}

En las frases en cursivas, el protagonista afirma haber engarzado acciones en su vida sin otra lógica que el encadenamiento desenfrenado. Si una acción de

\footnotetext{
2 Para insertar la cita coherentemente desde el punto de vista sintáctico, los corchetes modifican por ejemplo la persona, la terminación del verbo, una mayúscula/minúscula, etc.
} 
determinada extensión es a su vez una unidad temporal espacializada, la existencia sería un segmento de tiempo en el que se pueden encadenar un número variable de acciones: para el protagonista, estas unidades han de sucederse unas tras otras reduciendo lo más posible el intersticio que los une y prolongar ad infinitum la cadena de unidades espaciotemporales. El personaje parece encadenar obsesivamente acciones buscar protegerse de alguna brecha amenazante que pudiera abrir la falta de acción.

La prisa no concierne solo al encadenamiento de las acciones sino también a la realización de dichas acciones. En este caso, la prisa es, en una visión psicoanalítica, la descarga de una dosis sustancial de energía que el sujeto invierte en un objeto de modo puntual, inmediato y muy localizado. Es lo que Joël Birman llama "exceso", o sea la excitabilidad que en la psique genera una máxima espacialidad y una mínima temporalidad (2009: cap. 6). Es una presencia puntual cuyo funcionamiento se reduce al espacio del aquí y del ahora, sin expansión, sin ritmo y sin ningún horizonte, es decir sin temporalidad y por tanto sin posibilidad simbolizadora. Estamos en un presente desimbolizado. El exceso de excitabilidad sería, según Birman, una de las marcas del sujeto posmoderno y resultaría de su intención de evitar la experimentación de un malestar que íntimamente lo devora.

En este movimiento apresurado, el personaje de Manuel no parece estar en control: la energía que lo envuelve resulta incontrolable a la vez que da la impresión de control ("embebido [por] una velocidad que parece energía y es el vértigo de la caída libre" o "sin que participaran en ella ni mi voluntad ni mi conciencia"). Resultan acciones inauténticas y la existencia aparece como una sucesión de actos arbitrarios, un relleno de espacio y un vacío de sentido. Como el valium contra el insomnio que le acompaña, las acciones que va produciendo frenéticamente el protagonista son "graduales artimañas urdidas para sobrevivir sin entusiasmo" (5718). El personaje resulta encerrado en un círculo invisible en que piensa dominar lo que en realidad lo domina.

En cambio, el protagonista de El viajero del siglo concibe el movimiento como el fundamento de la experiencia empírica de la realidad, que significa para él lo sagrado de la existencia: "para mí, lo sagrado que tenemos son nuestros pies sobre la tierra" y "exploramos la tierra con [las emociones 
elevadas]" (212). Hans también se abandona a la energía soberana del movimiento: "creo que si sabes adónde vas y qué harás, lo más probable es que termines sin saber quién eres" (119). Pero este "abandono" es solo para mejor experimentar el presente en su asombrosa imprevisibilidad. Le gustan por ejemplo las diligencias que le permiten adivinar o inventar las vidas de los desconocidos con los que viaja; le exaltan las posibilidades (ínfimas pero sorprendentes) que puede ofrecer el espacio-tiempo único compartido por dos seres que probablemente no volverán a verse: "yo qué sé, mirando por ejemplo a una señora (...) podría decirle «señora, sepa que usted me importa», y habría una posibilidad entre mil de que en vez de mirarme como a un demente (...) podría confiarme «hace veinte años que nadie me lo decía»" (120). E personaje de Hans se consagra plenamente a su experiencia presente, invierte su ser y por ello, como Nadia, se emancipa de los dictados del tiempo objetivo de los relojes: "como si les correspondiera a ellos acompasarse a tu ritmo o estuvieras dispuesta a dedicar toda tu vida a cualquier cosa que haces", observa Manuel (Molina, 2010: 7402). Inmersos en la plenitud de la acción (la excepcional o la más banal), Nadia y Hans experimentan plenamente el presente arraigando el movimiento en lo simbólico, mientras que el personaje de Manuel se deja arrastrar por la vorágine de un movimiento que lo domina y en el que no invierte su voluntad.

Lo que encarcela al protagonista en esta prisa constante es el miedo, como afirmará explícitamente tras la toma de conciencia que le facilitó la conversación con Nadia: "quería seguir hablándote del miedo, y de lo que tal vez fuera su razón y su médula, la incertidumbre acerca de mí mismo, de mis deseos y mis sentimientos [:] la prisa" (5823, cursivas añadidas). Perdido, sin las referencias sólidas de los suyos y defraudado por la promesa del cosmopolitismo, Manuel concibe como única escapatoria la huida. Si la mente padece los asedios de la conciencia, los miedos, la culpabilidad en los momentos de inacción, uno ha de encadenar por tanto acciones, poniendo en marcha una nueva actividad o tapándose los ojos y los oídos ante la amenaza que se alza ante él ("sin mirar la delgada fisura de vacío que hay entre los dos"). Muy temido, este hueco temporal inactivo es la ventana por la que se asoma el sujeto hacia el precipicio del vacío. 
Originadas por el miedo y no por la voluntad íntima, las acciones se convierten en agitación vacía, en el "divertissement" de Pascal, al que se abandona el sujeto para embellecer el rostro de una existencia que, si la mira a la cara, es solo tedio: "en secreto, cumplo con una ficticia aplicación mis tareas" (1199). Es el neonomadismo descentrado. A él parece aludir el organillero de El viajero del siglo cuando insinúa una reflexión sobre la verdadera razón del movimiento: “¿eso es viajar o escapar?” (121). Ningún lugar, ninguna acción consigue detenerlo porque el protagonista no se encuentra nunca en adecuación con su circunstancia: está fuera de lugar. En la casa de Félix, el querido amigo de su infancia, Manuel afirma: "nada más entrar en el pasillo de su casa empecé a notar la cálida sensación de que al menos durante unas pocas horas no estaría del todo fuera de lugar" (6157). Llegar a un lugar no es nunca para quedarse, hacer algo no es nunca para aprovechar, porque estar en un lugar no es nunca estarlo del todo: "desalentado, nervioso, porque llegar a los sitios me deprime tanto como me excita irme de ellos, cargando no alfombras, sino horas muertas de tedio" (6135). La contradicción entre buscar algo solo para dejarlo enseguida define la inadecuación entre sujeto y espacio, como resalta también al final de la larga cita reproducida más arriba: "la urgencia angustiosa de apurar la noche y de que la noche no se termine". En su vida nómada y cosmopolita, se convierte en el miembro de una "raza aparte que vive en una diáspora sin persecución ni tierra prometida, nunca saben del todo dónde están, no terminan de acostumbrarse jamás al país donde se instalaron hace años, pero vuelven al suyo y advierten que han pasado fuera demasiado tiempo, que han perdido las claves cotidianas de su propio idioma" (5735). Por haber perdido los referentes sólidos, su identidad encuentra un equilibrio ilusorio y falaz en la huida, en un nomadismo descentrado cuanto más dinámico tanto más vacío.

\section{Manifestación de la identidad neonómada a través de la traducción}

En las dos obras, el nomadismo está vinculado con la actividad de traductor, marcada por el desplazamiento intenso entre distintos puntos geográficos. Pero al mismo tiempo, el nómada es a nivel metafórico el que viaja entre alteridades lingüísticas, entre varias voces y una pluralidad de mundos. 
No abordamos aquí el tema de la recuperación memorialística de las voces de los antepasados que ha ocupado a menudo a los comentadores de El jinete polaco. Por lo menos tradicionalmente, se suele percibir la experiencia de la traducción como un recorrido por la lengua, la cultura y el mundo del otro; en un abandonarse a sí mismo, el sujeto traductor se deja penetrar por la alteridad para hacer emerger al otro. ¿Cómo se sitúa la voz propia con respecto a las voces ajenas? A nuestro modo de ver, el análisis desde la traductología podría reflejar metafóricamente la posición del sujeto dentro del nomadismo identitario entre identidades y mundos ajenos.

Como ha señalado la crítica, en El jinete polaco, la traducción es una herramienta eficaz para metaforizar la imitación de las voces ajenas y la alienación del protagonista con respecto a sí mismo. La traductología distingue globalmente entre la traducción literal y la traducción libre. El traductor podría ser solo un transmisor ("un passeur") que traslada la sensibilidad del autor a un sistema lingüístico ajeno sirviendo de este modo como instrumento. Pero la traductología plantea sobre todo la cuestión de la voz propia del traductor: "les traductrices et traducteurs (...) s'offrent comme passeuses et passeurs sans pour autant sacrifier leur corps, leur empreinte, la résonnance singulière de leur présence intermédiaire", explica Antonin Wiser (2017: 5). Esta modalidad "poética" de traducir, que para Steiner (1975: 28) navega entre imitación, recreación, variación e interpretación describe una relación dialógica y de no subordinación con respecto al autor del texto. Una cocreación que, por oposición a la simple imitación, es el resultado de la afirmación de la sensibilidad personal du "passeur".

La traducción no es traición, sino interpretación y enriquecimiento: "[e]l traductor, apunta Geneviève Champeau en su análisis de la novela de Neuman, es un «superlector», que re-crea la obra en otra lengua, conservándole las cualidades literarias equivalentes, como una interpretación musical" (311). Muchas veces, la elección de tal o tal texto es la marca de una afinidad previa que sutilmente revela también algo sobre el traductor: "pourquoi je l'aime et pourquoi je le choisis lui, et comment je peux me détacher de lui de manière à ce qu'il m'aide à trouver ma voix plutôt qu'il l'étouffe par la sienne" (Yves Érard, 2017: 27). Así, Hans lamenta que "[s]iempre est[e]mos buscando 
la pureza [...], para mí el verdadero lirismo consiste en lo contrario, ¿en cómo decirlo? pura emoción impura". Esta visión procede de su filosofía inclusiva y de intercambio: a nivel literario, a través de la traducción cocreativa, como modo de vida, a través de su existencia entre las fronteras, o bien, a nivel geopolítico, en el rechazo de la óptica nacionalista de la "alemanidad" promulgada por Fichte. Asimismo, Hans admira a Nerval por ser un artista preocupado constantemente por las lenguas, por la traducción y por impregnarse en las culturas de otros países durante sus largas estancias en el extranjero. La frase “¡Al carruaje, señores!”, que concluye el poema "La parada” leído por Hans, le inspira a Sophie la observación "[m]uy propio de ti” (335). En la traducción, la simple elección es por tanto autorevelación, puesto que, comenta el lingüista Patrick Charaudeau "[i]l n'y a pas d'acte de langage qui ne passe par la construction d'une image de soi" (2014: 66). Al traducir, Hans asienta su propia subjetividad.

Para el personaje traductor de Muñoz Molina, las palabras ajenas que traducir están siempre impuestas, no hay elección por afinidad. La traducción es aleatoria y nada dice del traductor: "las palabras me empujan, me envuelven, me arrastran en cenagales de caligrafía, de discursos fotocopiados, de libros que se van escribiendo a medida que yo los leo e intento traducirlos" (3335). El protagonista se deja dominado, colonizado por la avalancha de palabras que lo penetran sin impedimentos: "me invaden y me poseen las otras palabras, las mentirosas". La traducción no se hace a cuatro manos. Manuel se presenta como un traductor "literal", una caja de resonancia de las voces ajenas, un simple punto de tránsito que recepciona y transmite sin recrear. Estamos lejos de la dinámica dialógica de Hans para quien "una traducción no se compone de una voz de autoridad y de otra voz que la obedece, es más un encuentro entre dos voluntades literarias" (317). Hans crea sentido mediante el lenguaje negociando significaciones entre varias alteridades: asienta su propia voz y se inserta en una dinámica simbólica de intercambio. En Manuel entrar en relación con las alteridades es para perderse, mientras que en Hans el diálogo es para encontrarse. A la experiencia vicaria responde la dialéctica, al nomadismo descentrado, el arraigado. 
La traducción metaforiza las relaciones con el otro que fundan la identidad. El personaje de Manuel parece carecer de verdadero centro gravedad identitario; como en la traducción se borra a sí mismo para dejarse poseer por la alteridad:

adoptaba otra voz, hablaba con alguien y se me contagiaba su acento, pero me pasa lo mismo con las opiniones o los estados de ánimo de otros, que se me contagian en seguida, por eso no soy capaz de sostener una discusión sin ponerme de parte del que está en contra mía ni me cuesta ningún trabajo aprender un idioma ni imitar una voz, Félix dice que podría haberme ganado la vida de ventrílocuo, es como viajar a otro país sin moverse, como cambiar de alma y de memoria, hasta de identidad. (5694)

El subrayado explicita la relación entre la identidad y la metáfora espacial del nomadismo. En un movimiento centrífugo, la identidad toma todas las direcciones sin seguir un hilo conductor, sin coherencia global. Siguiendo el modelo emblemático del ventrílocuo vila-matasiano, el sujeto es tributario del entorno, en completa disponibilidad ante la alteridad y con infinitas capacidades plásticas de la mismidad. El otro no es un mundo que descubrir en la aventura interhumana sino un instrumento de autoenmascaramiento: "[p]refería callarme, escuchar a otros, mirarlos y espiarlos, he usado mi voz para inventar o mentir o para enmascararme en las voces de los otros, [...] he vivido fuera de mí mismo, en una fronda de palabras, he salido de mí para perderme en ellas" (5679). La alienación del sujeto descentrado usa la máscara de la alteridad como subterfugio para huir, para "no estar". Suspende su propia voz, la especificidad de su propia identidad.

Nuestro análisis ha permitido constatar que obras como El jinete polaco y El viajero del siglo presentan, en la era de los grandes desplazamientos contemporáneos, posicionamientos distintos con respecto al nomadismo y a la pertenencia. Emitimos la hipótesis de un cambio de paradigma entre finales del segundo milenio y principios del tercero. Muñoz Molina y Andrés Neuman pertenecen a dos generaciones distintas, el primero por haber presenciado los inicios del dinamismo espacial internacional y el segundo por haber crecido con él tanto a nivel cultural como biográfico (argentino mudado a Granada en su adolescencia), dentro de un marco transnacional ya bien establecido. En el marco de esta evolución, la propia visión literaria de Muñoz Molina sobre el nomadismo puede que haya cambiado desde El jinete polaco de 1991 hasta su 
percepción más entusiasta para con el movimiento y la alteridad en Ventanas de Manhattan (2004) o Un andar solitario entre la gente (2018).

Para el personaje de Manuel, el centro es fundacional y está en el pasado. La pérdida o el rechazo de las raíces crea la "nostalgia for fixity" y lo lleva a un nomadismo compensatorio. Se abandona al cumplimiento de un presente repetitivo y solitario. Entre aquel pasado y este presente, el sujeto se encuentra en el limbo de la no pertenencia y su subjetividad a la deriva esboza una identidad descentrada y un nomadismo desarraigado. En El viajero del siglo el protagonista nómada construye una centralidad simbólica: experimenta plenamente el presente, se maravilla ante lo imprevisible y se abre a la alteridad. Estas últimas modalidades exigen detenerse, experimentar temporalizando, componente esencial del proceso de simbolización. El centro de gravedad de la identidad no es preexistente y no se recupera, se construye, está en el presente y evoluciona en un eterno devenir en el futuro. Este nómada experimenta así la paradoja maffesoliana de 'dinamismo arraigado', o sea el neonomadismo arraigado dinámicamente. Al nomadismo como huida del vacío, responde un nomadismo como gozo.

\section{BiBLIOGRAFÍA}

AugÉ, Marc (1991). Non-lieux. Introduction à une anthropologie de la surmodernité. Paris: Seuil, Coll. Librairie du XXle siècle.

Bachelard, Gaston [1957] (1974). Poétique de l'espace. Paris: PUF.

BAUMAN, Zygmunt (2010). Identité: entretiens avec Benedetto Vecchi. Paris: L'Herne

BAUMAN, Zygmunt (2009). "Identity in the Globalizing World". En Antony Eliott y Paul Guy (eds.), Identity in question. Los Angeles: Sage.

BIRMAN, Joël (2009). Cartographie du contemporain: Espace, douleur et détresse dans l'actualité. Paris: L'aventurine.

BRAIDOTTI, [1994] (2011). Nomadic Subjects. Nueva York: Columbia University Press.

Champeau, Geneviève (2017). "Cuando escribir es traducir: El viajero del siglo de Andrés Neuman". En Natalie Noyaret y Anne Paoli (ed.), L'écrivain à l'œuvre. Binges: Éditions Orbis Tertius.

Charaudeau, Patrick (2014). Le discours politique: les masques du pouvoir. Limoges : Lambert-Lucas.

Delleuze, Gilles y Guattari, Félix (1980). Mille plateaux, Paris: Editions du Minuit

De Terán, Manuel (1952). "Vida pastoril y nomadismo". Revista de la Universidad de Madrid. VI, 3, pp. 375-393. 
ERARD, Yves (StebleR, Joséphine y Antonin Wiser) (2017). "Conversation sur la traduction, l'intimité et l'étrangeté des langues" monográfico ", en $A$ contrario, monográfico "Passages", n. $\cong 24$, pp. 9-20.

GranAdo AlmENA, Víctor (2016). "Fuera de lugar: una reflexión arendtiana sobre el desplazamiento en la era global". Madrid: Universidad Complutense.

HARRINGTON, Katharine N (2012). Writing the Nomadic Experience in Contemporary Francophone Literature. Lexington: Lexington Books

IBÁÑEZ ERLICH María-Teresa (2002). "La ficcionalización de la Guerra Civil y posguerra españolas en "El jinete polaco" y "Beatus Ille" de Antonio Muñoz Molina", AEF, Vol. XXV.

KALUWEIT, Rolf (2008). "Postmodern Nomadism and the Beginnings of a Global

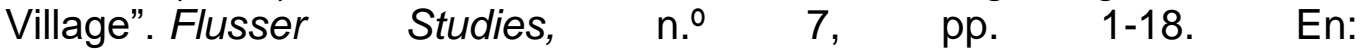
<http://www.flusserstudies.net/node/200> [Fecha de consulta: 24 de septiembre de 2021].

LEPELLEY, Claude. "Numides". En Encyclopédie Universalis. En: $<$ https://www.universalis.fr/encyclopedie/numides/>[Fecha de consulta: 24 de septiembre de 2021].

MAFFESOLI, Michel (1997). Du nomadisme, vagabondages initiatiques, Biblio Essais, Le Livre de Poche.

MuÑoz MolinA, Antonio [1991] (2010). El jinete polaco. Barcelona: Seix Barral. Versión Kindle.

MAINER, José Carlos (1997). "Antonio Muñoz Molina o la posesión de la memoria". En Irene Andrés-Suárez, Ética y estética de Antonio Muñoz Molina. Cuadernos de narrativa. Neuchatel: Université de Neuchatel, pp. 55-68.

OLEZA, Joan (2003). "Multiculturalismo y globalizacion: pensando historicamente el presente desde la literatura", Prosopopeya. Revista de crítica contemporánea, n. ${ }^{\circ}$ 4. En: <https://entresiglos.uv.es/wpcontent/uploads/multiculturalismo-y-globalizacio.pdf $>\quad$ [Fecha de consulta: 24 de septiembre de 2021].

SteINER, George (2017). After Babel. Aspects of Language and translation. Oxford: Oxford Université Press.

VILLODRE LÓPEZ, María del Pilar (2009). Reivindicación del pasado: una asignatura pendiente de la España democrática en la narrativa de Antonio Muñoz Molina. San Lorenzo de El Escorial: Ediciones Liberatias.

WISER, Antonin (2017). "Voix de passage". A contrario, n.․ 24, pp. 3-7.

Fecha de recepción: 20 de septiembre de 2021

Fecha de aceptación: 25 de noviembre de 2021 